\title{
EL RESURGIMIENTO DEL DERECHO ROMANO EN CHILE: PRESENTE Y FUTURO EN NUESTRAS UNIVERSIDADES
}

\author{
Prof. Dr. Patricio-Ignacio Carvajal**
}

Extracto del discurso pronunciado el día 21 de agosto de 2007 en el Salón del Pleno de la Excelentísima Corte Suprema, con ocasión de la inauguración del "Segundo Curso Interuniversitario de Profundización en Derecho Privado Romano" de la Schola Serviana Iuris Romani, Academia de Derecho Romano.

(...) Impresiona a todos los que de una u otra forma participan en el mundo jurídico chileno, la tremenda convocatoria que generan nuestros Cursos Interuniversitarios. Ya el año pasado contamos con 108 alumnos que cumplieron con el requisito de más de un $75 \%$ de asistencia; $y$, este año, todo indica que llegaremos prácticamente al doble de alumnos diplomados.

Esta impresión del resto del medio jurídico, a la que me refiero, es muy comprensible. Debe tenerse presente que no solo hemos superado ampliamente la asistencia de estudiantes a los eventos de otras disciplinas jurídicas de Derecho Positivo $-\mathrm{y}$, por tanto, con directa aplicación práctica-, sino, también, que nuestra disciplina, el Derecho Romano $-o$, dicho de otra forma, el estudio profundo del Derecho Privado-, enfrentó hace pocos años una "crisis universitaria".

Nótese que hablo de "crisis universitaria" y no de "crisis académica", porque la crisis de nuestra disciplina solo consistió en su supresión en el curriculum obligatorio de Licenciatura de unas cuantas Facultades de Derecho en el país. Pero, todo esto, a pesar de que en el resto del Mundo el estudio del Derecho Romano estaba, y está, conociendo un reflorecimiento de enormes proporciones; y de ahí que en ningún caso pueda hablarse de "crisis académica" del Derecho Romano.

Todos los procesos de unificación y sistematización del Derecho no han sido otra cosa más que un gran esfuerzo de reflexión en

* Presidente Schola Serviana Iuris Romani. Profesor Auxiliar Asociado de Derecho Romano, Facultad de Derecho, Pontificia Universidad Católica de Chile. torno al Derecho elaborado por los juristas romanos. Ya Justiniano fue un romanista; y, asimismo, Baldo, Bartolo, Domat, Pothier, nuestro Andrés Bello, Vélez Sarfield, Freitas, García Goyena fueron también romanistas. No extraña, entonces, que hoy, cuando a partir de los procesos de unificación del Derecho Europeo de Obligaciones y Contratos se ha iniciado un verdadero proceso mundial de unificación, protagonistas tan connotados como Gandolfi o Zimmermann sean, a su vez, romanistas. Han de saber ustedes que incluso las potencias asiáticas, las que a estas alturas ya han adoptado códigos civiles romanistas, se encuentran ahora en un acelerado proceso de traducción y estudio del Corpus Iuris Civilis.

En nuestro país, afortunadamente, el Derecho Romano está retomando su dos veces y media centenaria posición de primacía (pues el $250^{\circ}$ aniversario de la educación sistemática del Derecho en Chile, que este año celebra la Universidad de Chile, no es otra cosa que el inicio del estudio del Derecho Romano). "Res loquitur ipsa”, decía Cicerón; es decir, "las cosas hablan por si mismas": la enorme cantidad de alumnos que asisten a clases de Derecho Romano -incluso en las Facultades donde tan erradamente aún no se repone su calidad de asignatura obligatoria-, al igual que la misma presencia de ustedes hoy, dan cuenta de la actual fortaleza de nuestra especialidad. Una vez más: "res loquitur ipsa"

En mi opinión, este rápido reposicionamiento responde a la convergencia de dos flujos: uno interno, que se refiere a las necesidades de adaptación de nuestro propio Ordenamiento a la realidad actual; y, otro, externo, referido al proceso mundial de unificación del cual ya he 
hablado. A la manera de una consecuencia inevitable, ambos factores han despojado al Derecho Privado de las rígidas vestimentas proporcionadas por los Códigos, dejando brillar en plenitud, como si se tratara de su alma al desnudo, la naturalis ratio.

Así, hoy ya no convence señalar que tal o cual peculiaridad jurídica es así "porque lo dice la ley"; lo cual no deja de ser sorprendente, pues hasta no hace mucho esta era la solícita explicación a la que se remitían algunos profesores formados en una especie de tardía y anacrónica Ecole de l'Exégèse. Ciertamente esta respuesta ("porque lo dice la Ley") ya no satisface, y es ahí donde el Derecho Romano muestra toda su magnificencia como una colosal construcción del intelecto que está indisolublemente imbricada en la realidad social.

Por eso, si los alumnos asisten más a nuestros encuentros que incluso a muchos de Derecho Positivo, me parece que ello responde a que, con muy buen criterio, han percibido que "no hay nada más práctico que una buena teoria".

Si esto es así, quiero decirles que tienen ustedes toda la razón. Acaso solo deba agregar que, por otra parte, no hay mejor teoría que aquella a la que se puede arribar desde el estudio del desarrollo del Derecho Romano hasta nuestros días.

Lo que acabo de decir es un hecho y no un artilugio retórico de los romanistas. "Las cosas son como son", tal como ya lo decía Platón. $Y$, en este sentido, no se puede más que reconocer que, cuando hablamos sobre el Derecho chileno vigente, nuestra habla "es" una utilización de las palabras y del intelecto de los romanos. Hay algunos que no quieren reconocer este hecho de la causa; pero esto es lo mismo que le ocurría al burgués gentilhombre, de Moliere, que "hablaba en prosa sin saberlo".

Hasta hoy, no he conocido ninguna persona versada en Derecho, y en Derecho Romano, que le haya negado su paternidad respecto del Derecho actual. Es más, en una última pesquisa de sentencias del mundo anglosajón, he encontrado una sorprendente cantidad de fallos que recurren al Derecho Romano para fundamentar las instituciones del common law: así, por ejemplo, prácticamente todas las referidas a la cosa juzgada o a la novación presentan esta característica. Es que en aquel Derecho, con sus defectos y virtudes, hay que reconocer, como una de sus virtudes, que la falta de códigos que les permitan " $h a-$ blar en prosa sin saberlo" les impide, en consecuencia, negar las paternidades intelectuales.

Todo esto lo digo porque, como resabio de la "crisis universitaria" del Derecho Romano, algunas Facultades todavía insisten en la pseudosustitución de nuestra asignatura por alguna que pretenda explicar la "evolución de las instituciones jurídicas"; ya sea en el mundo occidental o, peor, en el mundo entero. Independientemente del hecho de ser un convencido de que, a la inversa de lo que se observa, debieran ser los romanistas quienes emprendiesen la tarea de explicar un curso de esa naturaleza -tanto por método, como porque han sido, de hecho, romanistas quienes han realizado los estudios más profundos al respecto-, veo con preocupación que esta perspectiva arranca de un inexcusable error: se pretende que ha sido la "evolución general" del mundo occidental la que nos ha traído hasta el actual estado de la ciencia jurídica. Entiéndase bien: una "evolución general" en el sentido de que todos los agentes han aportado más o menos por igual a este desarrollo. Mas, a estas alturas es bien sabido entre quienes se dedican al estudio del Derecho que, después de que en 1937 Edoardo Volterra escribiera su obra fundamental "Diritto Romano e diritti orientali", no cabe duda -en el sentido de que es un hecho histórico-, que ha sido el Derecho Romano, desde el inicio, el núcleo e hilo conductor de nuestro desarrollo jurídico.

Lo importante, en todo caso, es que el Derecho Romano goza de buena salud. Y lo auspicioso es que, con la implementación de la educación por competencias, dado su alto valor formativo, está llamado a tener un papel acaso más protagónico. En efecto, entre las destrezas más importantes de un jurista se encuentra la de su capacidad de análisis y la de su capacidad crítica: mas ninguna de estas puede alcanzarse si no se tiene también, entre toda una batería de recursos interpretativos, el conocimiento del verdadero desarrollo institucional y dogmático. 
Por ejemplo, un cierto desconocimiento histórico nos ha llevado a señalar que nuestro actual sistema de Título y Modo es idéntico al romano. Esto es, sin más, falso. Quien no conoce el Derecho Romano no puede jamás comprender lo que se nos presenta, prima facie, como verdaderas aporías de nuestro Código Civil en esta materia. Así, si es cierto que en nuestro Derecho se requiere ineludiblemente de la concurrencia de Título y Modo para toda adquisición, y con especial intensidad en las adquisiciones derivativas ¡cómo se entiende que, según el art. 1572, un tercero pueda pagar por el deudor, por ejemplo, una obligación de dar? Noten ustedes que si se trata de una obligación contractual, el acreedor, al que el tercero transfiere el dominio de la cosa debida, no puede invocar el contrato convenido con el deudor como Título de su adquisición. Y esto, por el hecho básico de que de los contratos no nacen más que derecho personales; de manera que, siendo la principal distinción entre los derechos personales y los reales que los primeros solo se pueden exigir al que contrajo la obligación correlativa -vale decir, al deudor-, mientras que únicamente los reales son oponibles erga omnes $-\mathrm{y}$, por tanto, a terceros-, si el acreedor invoca el contrato celebrado con el deudor respecto de la Tradición hecha por el tercero, cae en un error de Derecho. Así, como el contrato no se puede invocar como Título, en caso de que la obligación de dar sea cumplida por un tercero, tendríamos aparentemente una Tradición abstracta: es decir, un caso de transferencia de propiedad que rompería todo nuestro sistema, pues no requeriría de Título sino solo de Modo. Frente a esto, el romanista sabe perfectamente que solo la "causa solvendi" podría explicar satisfactoriamente esta anomalía llena de consecuencias. A pesar de que la "causa solvendi" no esté reconocida expresamente en nuestro Derecho, yo creo que sí lo está implícitamente a través de los elementos romanos que se encuentran recepcionados a lo largo de nuestra legislación, especialmente en las normas sobre el pago y el cuasicontrato de pago de lo no debido.

Afortunadamente, ustedes sí tienen la posibilidad de iniciarse en este conocimiento profundo del Derecho Privado. Realmente de- ben sentirse privilegiados, pues este Segundo Curso Interuniversitario será impartido por profesores de primera línea mundial. De hecho, con ocasión de este Curso nos han hecho llegar sus congratulaciones profesores de todas partes del mundo. Por nombrar algunos lugares: Italia, Alemania, España, Francia, Austria, Bélgica, Polonia, Bulgaria, Servia, Rusia, Hungría, Argentina, Colombia, Venezuela, México, Brasil y China.

El Curso, que ahora les ofrecemos, ha significado un gran esfuerzo de parte de todos los miembros de la Schola. Asimismo, cada uno de los profesores que intervendrá, a pesar de tratarse de académicos de larga trayectoria y reconocimiento, ha decidido colaborar de forma absolutamente gratuita, para lograr así un Curso que esté al alcance de la mayor parte posible de estudiantes. Otro tanto debemos decir de las prestigiosas Facultades que gentilmente nos han facilitado sus instalaciones para realizar nuestras sesiones. A todos ellos también debemos expresar nuestro profundo agradecimiento.

Sin perjuicio de lo anterior, el cuantioso aporte de una de las Facultades participantes ha sido indispensable para lograr la internacionalidad de este Curso: me refiero a la Facultad de Derecho de la Pontificia Universidad Católica de Chile. Me parece de toda justicia subrayar este decidido respaldo, sin el cual indudablemente no habríamos contado con un evento de la magnitud del que estamos inaugurando. Deseo agradecer con especial reconocimiento a esta Casa de Estudios, de la que orgullosamente formo parte, y cuyo Decano, Prof. Dr. D. Arturo Yrarrázaval Covarrubias, hoy ha tenido la gentileza de acompañarnos.

He dejado para el final mis agradecimientos para nuestro anfitrión del día de hoy. No existe ni la menor sombra de duda respecto de que este recinto, el Salón del Pleno de la Excelentísima Corte Suprema, es el más solemne, el más significativo, el de más alta dignidad en el que se pueda realizar una actividad académico-jurídica en nuestro país.

Es por ello que nos sentimos infinitamente agradecidos de la Excelentísima Corte por habernos abierto hoy sus puertas; y nues- 
tro sentimiento se duplica, si cabe, al constatar que nunca antes se había realizado una actividad de esta naturaleza en este lugar. Asumimos este exclusivo privilegio, debido al respaldo unánime del Pleno de Ministros, como un reconocimiento de la mayor trascendencia para el Derecho Romano. Por ello, deseo poner expresamente de manifiesto nuestra gratitud al
Excelentísimo ministro, señor Marcos Libedinsky, y, por su intermedio, a todos los Miembros del Pleno.

(...) Para concluir, como Presidente de la Schola Serviana Iuris Romani, declaro inaugurado este "Segundo Curso Interuniversitario de Profundización en Derecho Privado Romano". 


\section{REFLEXIONES EN TORNO A LA PROPUESTA DE REFORMA AL PROCEDIMIENTO CIVIL CHILENO}

\section{PRINCIPIOS PROCESALES RELATIVOS AL ÓRGANO JURISDICCIONAL}

\section{ROL DEL JUEZ EN EL PROCESO: PLANTEAMIENTO DE LA DISCUSIÓN}

Es un hecho indiscutible que la mayoría de los Códigos Procesales modernos han potenciado los poderes del juez en el conflicto civil. En general las diversas legislaciones procesales siguen recogiendo el principio dispositivo en cuanto a la iniciativa del proceso, su objeto y los hechos de la causa; empero han permitido el ingreso de notas inquisitivas en cuanto al impulso posterior del proceso y a la iniciativa probatoria.

No pocos critican la anterior tendencia. Se sostiene que las facultades procesales del juez deben ser sumamente limitadas, pues solo de ese modo se salvaguarda el derecho de defensa que asiste a las partes y que garantiza la seguridad jurídica.

Sostenemos que la implementación de un nuevo Código Procesal Civil supone necesariamente adoptar una decisión acerca de los principios ideológicos que deben sustentarlo. En tal sentido estimamos desechar, desde luego, la adopción de algunos de los modelos en debate (Dispositivismo y Autoritarismo) entendidos en su más extrema aplicación. Ha de adoptarse el principio dispositivo en plenitud en el nuevo Código y, aún más, deben precisarse sus alcances. Sin embargo, sostenemos que lo anterior es perfectamente conciliable con la idea de otorgar mayores poderes de dirección e impulso procesal al juez civil. En esa concepción no puede perderse de vista que si bien las partes son dueñas de los derechos subjetivos que se ventilan en el proceso civil, no son dueñas del proceso concebido como un instituto público.

El Estado dispone de recursos y pone a disposición de las partes en conflicto un instrumento para su resolución (el proceso). El juez es el representante del Estado en la rela- ción jurídico procesal que se forma en todo litigio. En esa perspectiva el proceso aparece en definitiva como un instrumento de pacificación social en el que el juez es el representante del Estado que no puede, sino, estar interesado en que el medio puesto a disposición de las partes (proceso) resulte fecundo en su labor final (la justicia y paz social).

Así las cosas, no parece razonable un juez que sea mero espectador en la relación jurídico procesal, cuestión que ha llegado incluso al extremo de permitir que muchas veces el proceso mismo haya sido utilizado para fines no solo ajenos, sino absolutamente contrapuestos, para los que ha sido concebido.

\section{JUEZ: DIRECTOR DEL PROCESO}

Considerado que el proceso debe ser un instrumento de pacificación social, en el que el juez no es un mero espectador sino un importante protagonista de la relación jurídico procesal que representa en definitiva los intereses del Estado y por ende el bien común, el juez debe constituirse en el DIRECTOR del nuevo proceso civil.

En doctrina se habla a este respecto del principio de autoridad para contraponerlo al papel de mero espectador del proceso a que se ha reducido al Juez por la aplicación estricta del principio dispositivo.

Naturalmente, ese poder de dirección debe ser un poder reglado y no libre, ya que el Juez deberá ejercerlo, en cada caso, de conformidad con las disposiciones expresamente establecidas en el nuevo Código.

Este poder de dirección que se sugiere, aunque en realidad debe considerarse en verdad un poder-deber de dirección, debe traducirse en el otorgamiento de mayores facultades de las que hoy dispone el juez civil, pero siem- 
pre precisamente regladas de modo de evitar el abuso que puede llegar a implicar su consagración genérica.

Resulta fundamental también dejar claramente establecido que este nuevo carácter del juez civil debe referirse únicamente a otorgar mayores o nuevas facultades de índole exclusivamente procesal. Las facultades materiales deben seguir permaneciendo radicadas excluyentemente en las partes en conflicto.

\section{A. FACUlTades AL INICIO DEL PROCESO}

Pobres e insuficientes son las facultades actuales del juez al inicio del proceso, esto es, al momento de los que se denominan actos de proposición (demanda y contestación). En la actualidad encontramos únicamente la facultad oficiosa del juez de no dar curso a la demanda que no cumple algunos de los requisitos legales (arts. 254 y 256 del C. P. C. )

Evidentemente que al principio de economía procesal repugna lo anterior, toda vez que no se condice con las exigencias de una justicia rápida y eficiente, la utilización del esfuerzo jurisdiccional de muchos para la tramitación de cuestiones improponibles o claramente improcedentes. Lo anterior exige aplicar con autoridad el principio de oportunidad, facultando al juez para rechazar in limine: 1. las demandas cuando fueren manifiestamente improponibles o cuando carezcan de los requisitos formales exigidos por la ley; 2. las demandas en que quede de manifiesto la falta de legitimación o de interés del actor; 3. la demanda que contenga una pretensión sujeta a un plazo de caducidad que aparezca vencido; 4. demandas en que aparezca de manifiesto el incumplimiento de alguno de los presupuestos procesales de existencia o validez; 5. demandas en que se solicite la aplicación de un procedimiento que no es el dispuesto por la ley. Las resoluciones que el juez dicte en tales casos, por cuanto ponen término al procedimiento, deben quedar sujetas a revisión del superior jerárquico por la vía del recuso de apelación, sin perjuicio de permitir la subsanación de sus defectos, en breve plazo, cuando ello fuere posible.

\section{B. Facultades Relacionadas CON LA MEDIACIÓN Y ARBITRAJE}

Se sugiere facultar al juez para que, una vez que haya conocido los actos de proposición y defensa, pueda obligar a las partes a iniciar un proceso de mediación y de posterior arbitraje siempre y cuando concurran las siguientes circunstancias: 1 . que se trate de conflictos de alta complejidad técnica y de importante cuantía. Deben descartarse por consiguiente asuntos que, aún siendo de elevada cuantía, se resuelvan conforme a normas comunes o principios generales del derecho; 2 . para tales efectos, el juez deberá citar a una audiencia con el preciso objeto de proceder al nombramiento de la persona del mediador, mismo que desempeñará la calidad de árbitro para el caso que el proceso de mediación fracase; 3. la facultad referida podrá ser ejercida por el juez una vez conocidos los actos de proposición y defensa y solo hasta antes de dictar la providencia con la que debe dar curso al proceso; 4. el uso abusivo o erróneo de la facultad señalada puede ser sancionado con medidas disciplinarias para el juez.

\section{Facultades durante el CURSo Del PROCESO: IMPULSO Y CELERIDAD PROCESAL \\ Así como en virtud del principio dis-} positivo solamente a la parte le compete la iniciación del proceso, una vez iniciado o promovido este, debe competer al juez adoptar las medidas consiguientes para que el proceso se desenvuelva rápidamente y evitar su paralización.

En nuestro actual Código de Procedimiento Civil se pueden encontrar numerosas disposiciones que obligan al juez a dar curso progresivo al proceso, sin esperar la actividad de las partes. No obstante, es evidente que en la práctica no han sido de mayor utilidad pues se ha entendido que el impulso procesal les corresponde a las partes.

Por consiguiente, y como principio debe establecerse la facultad-deber del juez de dar curso progresivo al proceso y evitar la paralización del mismo, en los siguientes términos: al juez le corresponde dar curso al proceso pero solo para pasar de un estadio procesal 
a otro dentro del procedimiento de que se trate; el incumplimiento de esta obligación deberá acarrear las sanciones disciplinarias correspondientes; solo a las partes les corresponde el impulso e iniciativa procesal para avanzar dentro de cada estadio procesal; el abandono del procedimiento sigue plenamente vigente como instituto procesal, pero que tendrá lugar solo cuando la inactividad de las partes se produce dentro de un determinado estadio procesal.

\section{FACULTADES EN MATERIA DE PRUEBA}

En esta materia debe dejarse claramente establecido que el objeto de la prueba civil no es el hallazgo de la verdad material. Su auténtica función es lograr la certeza del juzgador acerca de los hechos afirmados y controvertidos por las partes.

Deben regir en plenitud las siguientes premisas: 1. solo los hechos afirmados por las partes existen para el juez; 2. únicamente cuando los hechos afirmados por las partes resultan controvertidos es posible realizar actividad probatoria; 3. la prueba en el proceso civil no comporta una actividad de investigación, sino de mera verificación de aquellos hechos que, afirmados por las partes, resultan controvertidos.

En nuestro Código actual queda de manifiesto que la prueba es "cuestión de las partes", estando el Tribunal limitado a cierta actividad probatoria oficiosa a través de denominadas Medidas para Mejor Resolver. Estas solo pueden ser decretadas dentro del período de que dispone el sentenciador para dictar sentencia.

Sin embargo, es evidente que el hecho de entender en su máximo extremo el que la prueba es cuestión de las partes, como ocurre en el actual sistema, lleva muchas veces a que la actividad jurisdiccional resulta infructuosa y, lo que es mucho más grave, permite la colusión entre partes y el fraude procesal al tolerarse "supuestos conflictos jurídicos" en que sobre la base de hechos admitidos se obtienen sentencias que lesionan intereses y derechos de terceros.

En razón de lo anterior se propone aumentar las facultades probatorias del juez en términos que este podrá decretar la práctica de todas clases de diligencias probatorias, ya sea durante el curso del proceso o como medidas para mejor resolver, al menos en los casos que: 1. el material probatorio existente en el proceso sea insuficiente en términos de que el juez no haya podido lograr convicción acerca de los hechos controvertidos; 2. aparezcan hechos nuevos que sean relevantes para resolver la controversia, pero solo en cuanto esos hechos van a servir para acoger o rechazar la demanda. Debe respetarse el principio de congruencia; 3. la prueba del Derecho Extranjero pueda servir para resolver el conflicto; 4. el juez sospeche la existencia de fraude o colusión procesal. En este evento debe estar facultado, además, para hacer citar al proceso a quienes aparezcan como posibles víctimas del fraude o colusión.

Se propone también que el juez esté facultado para desechar de plano y sin ulterior recurso toda prueba inconducente, impertinente o puramente dilatoria.

FERNANDO ROMÁN DÍAZ Profesor Adjunto de Derecho Procesal, Facultad de Derecho, Pontificia Universidad Católica de Chile 



\section{PRINCIPIOS PROCESALES RELATIVOS A LAS PARTES}

\section{PRINCIPIO DISPOSITIVO}

El principio dispositivo entendido como aquel en virtud del cual las partes poseen dominio completo tanto sobre su derecho subjetivo sustancial como sobre sus derechos a la iniciación, desenvolvimiento y culminación del proceso, debe ser establecido y precisado en un nuevo Código Procesal Civil.

Este debe ser un principio pilar de la reforma procesal civil, por cuanto no hace más que garantizar y respetar la libertad individual de los justiciables. El principio dispositivo además, no es otra cosa que un derivado de la naturaleza eminentemente particular de los derechos o intereses en juego en el conflicto civil.

Además, no es un principio absoluto dado que tiene como lógica limitación la presencia de derechos indisponibles que el juez debe proteger aun contra el consentimiento de la parte afectada. Asimismo, en caso alguno debe permitir a las partes disponer de las normas procesales.

Por ello se propone consagrar expresamente el principio dispositivo, precisando sus términos y limitaciones en la forma que, 1 . La iniciativa en la instauración o iniciación del proceso incumbe solo a los interesados. Ningún proceso puede comenzar por iniciativa del propio órgano jurisdiccional (ne procedat index ex officio: "que el juez no proceda de oficio") sino solo por la solicitud de un sujeto jurídico que pretende obtener una resolución jurisdiccional concreta; 2. Exista la disponibilidad de las partes sobre el proceso, donde las partes pueden libremente disponer de sus derechos en el proceso, salvo aquellos que por ley sean declarados como indisponibles. La disponibilidad o indisponibilidad del derecho debe ser calificada por el juez al momento de resolver una petición concreta. De esta forma las partes pueden terminar el proceso en forma unilateral o bilateral. En forma unilateral el actor puede desistirse de la pretensión o renunciar a su derecho, el demandado puede desistirse de su oposición a la pretensión o puede allanarse a la demanda, y uno u otro pueden desistirse de uno o más actos procesales o pueden someter el proceso a la resolución de un tribunal arbitral; 3. Los hechos que constituirán el thema decidendum, es decir los hechos objeto del proceso, solamente pueden ser aportados por las partes. Los hechos admitidos por las partes, los hechos que las partes no controvierten se imponen al Juez, a menos que se trate de un caso de fraude o colusión procesal; 4. El juez debe respetar el principio de congruencia con arreglo al cual debe fallar las cuestiones litigadas por las partes y conforme a las pretensiones deducidas. En la sentencia definitiva el juez solo podrá esgrimir argumentos o normas jurídicas no alegadas en la medida que respete el principio de congruencia, esto es, sin que nada añada al objeto del proceso; 4. por último, debe establecerse como limitación al principio dispositivo la indisponibilidad de las normas procesales, en términos que las partes del proceso no pueden acordar, por anticipado, dejarlas sin efecto o modificarlas, salvo en materia arbitral. El orden consecutivo legal impide, naturalmente, que las partes puedan, anticipadamente modificar en cualquier sentido que fuere las normas procesales. Con todo, debe precisarse que esta indisponibilidad se refiere a la renuncia o la modificación anticipada de las normas procesales, como sería, por ejemplo, la renuncia -expresa o tácita- de una de las partes a interponer recurso de apelación contra la sentencia definitiva.

\section{PRINCIPIOS DE IGUALDAD PROCESAL Y BILATERALIDAD}

No existe en nuestra legislación norma expresa que consagre la igualdad procesal de las partes, ni su derivado consustancial, el principio de la bilateralidad de la audiencia. Lo que sí tiene amplia acogida en la práctica judicial es la malentendida aplicación de la bilateralidad de la audiencia, conforme a la cual los jueces estiman indispensable la necesidad de oír a la contraparte aun cuando se trate de asuntos de fácil resolución, tanto porque cons- 
tan del proceso o bien por existir norma legal expresa y precisa que los dirima.

Evidentemente ambos principios pueden colegirse de numerosas disposiciones; sin embargo resulta indispensable su consagración expresa, por cuanto no son un postulado meramente teórico y su formulación clásica no constituye una mera proclamación retórica. Estos deben ser principios de los que se deduzcan conclusiones jurisprudenciales.

Es una verdadera exigencia del proceso jurisdiccional, como instrumento de la justicia, el postulado de que los distintos sujetos del proceso -quien solicita una decisión jurisdiccional y aquel contra o frente al cual tal decisión se solicita- dispongan de iguales medios para defender en el proceso sus respectivas posiciones, esto es, dispongan de iguales derechos procesales, de posibilidades equivalentes para sostener y fundamentar lo que cada cual estime que le conviene.

Por cierto que esta igualdad procesal no significa que las partes de un proceso sean iguales. Es evidente que no lo son. Existe una desigualdad intrínseca y funcional de las partes (actor o demandante y demandado). No es ni puede ser igual quien ataca, por así decirlo, que quien, en principio, es atacado. $\mathrm{Ni}$ es igual ni le corresponde, en consecuencia, jugar en el proceso igual papel.

Pues bien, sin perjuicio de la desigualdad esencial de las partes en el proceso civil, tal desigualdad no impide y es compatible con que, en cuanto a las actuaciones decisivas del proceso, las partes gocen de oportunidades sustancialmente iguales o equivalentes para sostener sus posturas.

En el Derecho Procesal, la aplicación del principio constitucional de igualdad de las personas ante la ley se traduce en el principio de bilateralidad de la audiencia. Como señala Couture, dicho principio se resume en el precepto audiatur altera pars, es decir, óigase a la otra parte.

Con todo se debe estimar que el contenido del principio de bilateralidad de la audiencia se circunscribe a impedir una resolución jurisdiccional perjudicial o condenatoria de quien no haya podido, en absoluto, intervenir en el proceso correspondiente.
En la legislación extranjera puede citarse el caso del Código General del Proceso Uruguayo que consagra la igualdad de las partes en los siguientes términos: "El tribunal deberá mantener la igualdad de las partes en el proceso".

Pues bien, estimándose tal vez poco precisos los conceptos del Código Uruguayo, se propone consagrar los principios procesales señalados en los términos a continuación.

El Tribunal debe mantener un trato igualitario frente a las distintas partes del proceso. No podrá el juez, por consiguiente, limitar las oportunidades de las partes para sostener sus defensas en términos de hacerlas sustancialmente desiguales o desequivalentes entre ellas. Lo anterior es sin perjuicio de aquellos casos en que la limitación está dispuesta por la propia ley.

Se deberá facultar al juez para dictar las resoluciones o disponer las medidas que estime pertinentes para restablecer la falta de igualdad de oportunidades que puedan haberse dado en un caso concreto.

Nadie podrá ser condenado sin haber tenido la posibilidad de ser oído en el proceso respectivo. La imposibilidad absoluta de ser oído deberá acreditarse fehacientemente ante el Tribunal.

La bilateralidad de la audiencia no impide la condena en rebeldía voluntaria del perdedor, ni tampoco impide la resolución inmediata de cuestiones que el juez puede o debe fallar sin necesidad de oír a todas las partes del proceso.

\section{PRINCIPIO DE BUENA FE Y DE LEALTAD PROCESAL}

El principio de la Buena Fe Procesal impone a las partes litigantes el deber rectitud, honradez y buen proceder en la defensa de sus intereses jurídicos en el marco de un proceso judicial. Les exige a los contendientes una actuación leal en el uso de pretensiones, defensas o recursos, debiendo sancionarse por ende cualquier exceso en el caso de expedientes dilatorios o pretensiones infundadas.

Estimamos superada la discusión acerca de si estos principios de buena fe y de lealtad procesal deben ser realmente normas jurídicas 
exigibles o, por el contrario, apenas aspiraciones o recomendaciones éticas. Es deber el establecimiento expreso de tales principios en el nuevo Código Procesal Civil, consagrando además sanciones claras y precisas para el incumplidor.

Aquí interesa como nunca la consagración expresa del principio, pero por sobre todo interesa también las aplicaciones prácticas del mismo y las sanciones para su incumplimiento.

En nuestro sistema procedimental actual, las normas de enjuiciamiento que supuestamente son emanación de este principio v. gr. multas al litigante temerario, condenación en costas, etc. tienen escasa aplicación práctica. Los jueces civiles se muestran reacios a dar aplicación estricta, severa y enérgica a estas normas, lo que sumado a la escasez de herramientas con que cuentan para evitar el fraude y la mala fe, ha degenerado en que los principales responsables del retardo injustificado en la administración de justicia sean los propios letrados, los que por la vía de los incidentes y recursos meramente dilatorios desvían los esfuerzos jurisdiccionales hacia cuestiones que nada tienen que ver con lo realmente debatido en el proceso.

En el Código Procesal Modelo para Iberoamérica, la oralidad, inmediación y concentración constituyen pilares fundamentales que claramente fomentan la lealtad del debate. Siempre se ha dicho que el papel lo aguanta todo y obviamente son pocos los litigantes que osan interponer incidentes meramente dilatorios y carentes de todo fundamento ante la presencia física de un Juez enérgico, que además cuenta con las herramientas procedimentales para poner atajo a tales conductas.

En el artículo $5^{\circ}$ del código citado se señala que las partes, sus representantes o asistentes $\mathrm{y}$, en general, todos los partícipes del proceso, ajustarán su conducta a la dignidad de la justicia, el respeto que se deben los litigantes y la lealtad y buena fe. El tribunal deberá impedir el fraude procesal, la colusión y cualquier otra conducta ilícita o dilatoria. Pero lo más importante es que se faculta expresamente al juez civil para sancionar a quienes observen una conducta incompatible con el decoro y dignidad de la justicia, con multas y arrestos.

En consecuencia y en lo que a este acápite respecta, se sugiere no solo consagrar en términos generales la obligación de guardar el principio de la buena fe y lealtad procesal, sino que además establecer mecanismos claros y precisos que la garanticen. Para tales efectos se propone la oralidad e inmediación como principios que necesariamente desalientan e inhiben el comportamiento desleal del litigante. Que la exigencia de que tanto el actor en su demanda como el demandado en su contestación acompañen toda la prueba documental que intenten hacer valer y propongan concretamente los restantes medios de prueba. Es decir, y para expresarlo de manera gráfica, se debe exigir que ambas partes pongan todas sus cartas sobre la mesa desde el inicio mismo del proceso, evitándose de plano ocultamientos y maniobras. Se propone además, la aplicación de sanciones disciplinarias y multas a los litigantes y abogados que desatiendan a los deberes de buena fe y lealtad procesal, como también se debe facultar al Tribunal para decretar todas las medidas necesarias para impedir el fraude procesal, la colusión y cualquier otra conducta ilícita o dilatoria, incluso la realización de diligencias probatorias de hechos admitidos y la citación al proceso de terceros que puedan aparecer perjudicados. Finalmente, se debe sancionar la conducta atentatoria de tales principios con la facultad del juez de rechazar la pretensión de que se trate sin más trámite (aplicación de la teoría de los actos propios del derecho civil al proceso).

EugENIO BENÍTEZ RAMÍREZ Profesor Auxiliar Asociado de Derecho Procesal, Facultad de Derecho Pontificia Universidad Católica de Chile 



\section{PRINCIPIOS PROCESALES RELATIVOS AL PROCEDIMIENTO}

Desde principios de siglo, tanto la doctrina nacional como la extranjera se han ocupado de desarrollar aquellos principios que han de regir al proceso civil. Muy larga ha sido la discusión entre los autores en cuanto a cuáles deben ser los principios sobre los que deben fundarse los procedimientos civiles para cumplir con los fines que le son propios, es decir, para ser un verdadero instrumento de pacificación y de justicia en una sociedad en que las personas están privadas de la posibilidad de resolver por mano propia.

Nuestro trabajo se centra en la búsqueda de aquellos principios cuya consagración en normas concretas permitiría asegurar a las personas un procedimiento civil que sea justo, rápido y económico. Los principios procesales que a nuestro juicio, aseguran de manera más efectiva lo anterior, son los principios formativos de oralidad, inmediación, concentración y publicidad.

\section{ORALIDAD}

Como diagnóstico de la actual situación, puede decirse que el proceso civil chileno muestra una clara preeminencia de la escrituración por sobre la oralidad. A modo de ejemplo, podemos decir que el procedimiento común en Chile, es decir, el juicio ordinario, es un procedimiento esencialmente escrito, lo que provoca una enorme lentitud de los procesos y una desconexión entre el juez y las pretensiones de las partes.

Sin embargo, la preeminencia de la escrituración no es absoluta. Incluso en el juicio ordinario la ley contempla que determinadas actuaciones se realicen en forma verbal, como por ejemplo, en el caso de las declaraciones de testigos y la confesión judicial. Además, la ley procesal chilena contempla también algunos procedimientos civiles en los que la oralidad toma fuerza frente a la escrituración, como el juicio sumario, los interdictos, los juicios especiales de arrendamiento.
No obstante la aplicación, la práctica de la escasa oralidad consagrada en nuestro sistema es simplemente nula. En los procedimientos en los que la oralidad es permitida (sumario, por ejemplo), la ley se ha encargado también de establecer la posibilidad de presentar minutas escritas lo que, en definitiva, ha determinado que el procedimiento sumario sea en la práctica escrito.

Debe entenderse que si la ley permite la oralidad como excepción y la gran mayoría de los procesos son escritos, entonces la oralidad está destinada a la inoperancia, como efectivamente ocurre en nuestro actual sistema procesal. Por ello, estimamos que el nuevo Código Procesal Civil debe hacer una opción radical, en términos de consagrar la oralidad como principio formativo del proceso que sea aplicable a la gran mayoría de los actos procesales. La escrituración será la excepción limitada a ciertos actos procesales específicos y puntuales.

Debe considerarse además, como sustento fundamental de la oralidad, que la idea de consagrar un proceso civil declarativo que pretenda obtener realmente la inmediación y la concentración, ha de estar construido sobre la predominancia de la oralidad, lo que además conlleva ciertas exigencias técnicas que no afectan solo a la forma de los actos, sino que implican un entero modelo de administración de justicia civil. La inmediación y la concentración de los actos procesales son imposibles sin oralidad.

Por de pronto, no puede ponerse en duda que la palabra hablada es la forma idónea de comunicación del ser humano con sus pares, ya que permite un mayor y mejor entendimiento y porque los dichos oscuros o poco claros se dilucidan en el acto. Además, la oralidad permite la facilidad y sencillez de la relación entre las partes y el juez, quien, al estar en contacto directo con estas y sus declaraciones, como asimismo con las de los testigos, puede evaluar la espontaneidad de las personas que han actuado ante él. Si bien la oralidad implica necesariamente un mayor 
aporte de recursos a la función jurisdiccional, ese mayor gasto se ve atenuado con la consiguiente economía procesal que implica la necesaria concentración de los actos orales del proceso.

Por último, nos ha parecido que la objeción de liviandad de la decisión jurisdiccional y las eventuales sorpresas de los litigantes que podría implicar la oralidad, dejan de estar latentes si acaso dicho principio formativo no se asume en todo su extremo, consagrando, por ejemplo, la escrituración para todos los actos de proposición (demanda y contestación). Por lo demás ello se justifica plenamente si se toma en cuenta el elevado nivel de complejidad del contenido de los conflictos que hoy se presentan en la sociedad moderna. Así pues, el rol de la escrituración en el nuevo proceso civil sería precisamente el de preparar el debate oral que luego deberá desarrollarse a lo largo de una o más audiencias en el proceso.

Tomando en cuenta las ventajas y los inconvenientes que hemos señalado, hemos llegado a la conclusión de que la futura reforma procesal civil no debe caer en la tentación de llevar la oralidad en el proceso civil al extremo. Mucho más conveniente nos ha parecido la instauración de lo que podría llamarse un sistema "mixto" en el que tanto la demanda como la contestación de la demanda deban plantearse por escrito, proveyendo así al tribunal de una fuente a la que se puede recurrir para una mejor comprensión y estudio del asunto que se somete a su decisión, dejando la recepción de la prueba y la resolución de incidentes para audiencias verbales presididas personalmente por el juez, concentradas y poco distanciadas unas de otras.

\section{INMEDIACIÓN}

En relación al principio de inmediación, debemos concordar en que este prácticamente no tiene aplicación en el proceso civil chileno. El distanciamiento y lejanía de las partes y sus abogados con el juez es notable. En la práctica judicial, este funcionario público técnicamente preparado, se ha desvinculado de los procesos que se siguen ante él, delegan- do gran parte de las funciones que le son propias en funcionarios de rango menor, muchas veces de escasa preparación. Las partes y sus abogados, quedan la mayoría de las veces en manos de una serie de funcionarios que proveen escritos, toman audiencias y reciben la prueba sin estar técnicamente capacitados para hacerlo, quedando la figura del juez cada vez más lejana.

En efecto, en la actualidad los jueces civiles solo toman conocimiento de los procesos que se siguen ante ellos al momento de estar en condiciones de pronunciar la sentencia definitiva. Solo en ese momento deben resolver basándose exclusivamente en lo que se les presenta a través de un tercero y en forma escrita, sin haber podido formarse una impresión propia de las pretensiones de las partes ni de la prueba rendida.

Si bien hemos estimado como altamente conveniente la consagración del principio de inmediación en nuestra legislación, aquella no pasará de ser una simple aspiración si acaso no se establecen al mismo tiempo sanciones de carácter procesal y administrativo para el caso de incumplimiento.

Para nosotros la consagración de la inmediación implica el establecimiento de un poder-deber del juez de escuchar y fundamentalmente dialogar con las partes implicadas, con sus abogados, con los testigos y peritos, lo que le permite ponderar no solamente las palabras, sino que también actitudes, gestos, etc.

A nuestro juicio la futura reforma procesal civil debe consagrar la inmediación como principio básico de la misma, estableciendo claras sanciones procesales para su incumplimiento.

\section{CONCENTRACIÓN}

Similar diagnóstico del anterior es el que debe hacerse en relación a este principio procesal. En efecto, en la actualidad el principio de concentración casi no tiene aplicación en el proceso civil chileno. La demora de los procesos y la dilación innecesaria llegan a extremos insólitos, al punto de constituir una verdadera denegación de justicia. 
La concentración, entendida como aquel principio en virtud del cual se procura abreviar en el tiempo el desarrollo del proceso, haciendo que sus actos se produzcan en forma continuada, sin interrupciones ni interferencia, está lejos de recibir aplicación en nuestro actual sistema procesal civil.

Reacción a la desconcentración de los actos procesales imperante en nuestro sistema, es la Ley que crea los nuevos Tribunales de Familia que consagra dentro de los principios formativos del procedimiento el de concentración de los actos procesales. La referida ley dispone que el procedimiento debe desarrollarse en audiencias continuas y que puede prolongarse en sesiones sucesivas, hasta su conclusión. Otro buen ejemplo del cambio anotado está dado por las normas del nuevo sistema procesal penal, que permiten anular el juicio oral en que hubieren sido violadas las disposiciones sobre continuidad del juicio.

A nuestro juicio, la aplicación del principio de concentración de los actos procesales en el nuevo sistema procesal civil es una necesidad, por cuanto no solo redunda en la rapidez del proceso judicial, sino que también disminuye los costos económicos del mismo y constituye un buen medio para mejorar la calidad de las sentencias que se dicten. Mientras más cerca esté la sentencia de los actos del proceso, mejor será la memoria del juez al respecto y, por consiguiente, mejor será su decisión.

Para la consagración de la concentración en nuestro sistema procesal civil, se propone establecerla como principio formativo, señalando que los actos procesales deberán realizarse sin demora, quedando facultado el juez para abreviar los plazos cuando la ley lo permita y las partes para hacerlo siempre por mutuo acuerdo. Las obligaciones de concentrar en un mismo acto las diligencias que sea menester realizar y rendir toda la prueba en una o más audiencias contiguas y sucesivas hasta su conclusión, en las que deberán interponerse y fallarse los incidentes relativos a la misma. Por último, la fijación de plazos máximos dentro de los cuales el juez debe citar a las partes a la primera audiencia del proceso, una vez concluidas las presentaciones escritas de sus pretensiones y defensas.

\section{PUBLICIDAD}

En la actualidad, existen principalmente dos realidades opuestas en relación a la publicidad de los procesos. Mientras la reforma procesal penal ha instaurado un sistema de enjuiciamiento moderno, basado en audiencias a las que cualquiera puede asistir y en las que se permite incluso la transmisión televisiva, nuestro sistema procesal civil se mantiene anclado en el pasado, donde la aplicación de lo dispuesto por el artículo 9 del COT ("Los actos de los tribunales son públicos, salvo las excepciones expresamente establecidas por la ley") se reduce a permitir el acceso libre a los expedientes.

La señalada realidad no resulta aceptable si acaso se considera que, si bien el proceso civil afecta principalmente los intereses de los propios litigantes, no es menos cierto -como bien dice Alsina- que la sociedad toda se siente conmovida cada vez que se requiere la intervención judicial y que le interesa conocer la forma en que se administra justicia.

En relación a lo anterior, el principio de publicidad viene a constituir una verdadera garantía para los ciudadanos, toda vez que la posibilidad de percibir directamente los actos que se realicen en el ámbito judicial permite a la opinión pública controlar las acciones de los jueces y hacer efectiva, en su caso, su responsabilidad funcionaria. En palabras de Couture, el principio de publicidad constituye "el más precioso instrumento de fiscalización popular sobre la obra de magistrados y defensores".

Si bien la publicidad de los actos procesales puede en cierta medida ser una realidad en el proceso escrito, no cabe duda de que su aplicación se facilita y sus beneficiosos efectos se multiplican cuando va de la mano con la oralidad. Un proceso civil oral y público permitiría a las personas entender el sistema de administración de justicia imperante y conocer de mejor manera sus derechos, despojando al sistema judicial de aquella imagen de "mundo desconocido" forjada bajo el actual sistema y que se ha generalizado en la opinión pública. 
Sin embargo, entendemos que la publicidad de los actos procesales es solo un medio para lograr los fines que hemos indicado, y no un fin en sí misma, por lo que debe reconocer ciertos límites, reservando del conocimiento público determinados asuntos o actos. Por esto se propone consagrar el principio de publicidad como la regla y la reserva o secreto como excepción, siendo garantía del primero la instauración de un procedimiento civil oral y de audiencias.

Juan Pablo Domínguez Balmaceda Profesor Auxiliar Asociado de Derecho Procesal, Facultad de Derecho Pontificia Universidad católica de Chile 


\section{NOTAS SOBRE LA OBJECIÓN DE CONCIENCIA Y LA VENTA DE PRODUCTOS FARMACÉUTICOS}

La Dirección de la Revista Chilena de Derecho invitó a participar en la sección de Ensayos y Crónicas a los profesores de Derecho: Javier Couso ${ }^{1}$ y Matías Guiloff ${ }^{2}$, de la Universidad Diego Portales, y Rodrigo Delaveau ${ }^{3}$, de la Pontificia Universidad Católica de Chile, para que cada equipo respondiera tres preguntas relativas a un tema que despertó gran interés en el medio jurídico nacional. Se trataba, en efecto, de la negativa de venta de un fármaco en farmacias nacionales y el argumento sobre la objeción de conciencia, de acuerdo al Art. 19 No 6 de la Constitución Política de la República, invocado como una razón que justificaría tal negativa de comercialización.

Sin perjuicio de la forma en que dicha situación puntual llegue a resolverse, la materia es de interés actual y se proyecta a múltiples instancias.

El resultado de este ejercicio fue el siguiente:

\section{En materia farmacéutica, ¿cabe hacer objeción de conciencia, de acuerdo al Art. 19 No 6 de la Constitución Política de la República?}

J. C. y M. G: "El debate surgido a propósito de la distribución en las farmacias nacionales de la denominada 'pildora del día después' plantea una serie de cuestiones de carácter filosófico, constitucional, legal y reglamentario. En este breve texto, sin embargo, nos limitaremos a responder las muy precisas

${ }^{1}$ Javier Couso, Abogado Universidad Católica de Chile, Ph.D. en Jurisprudence and Social Policy, Universidad de California-Berkeley, Master (M.A.), en Jurisprudence and Social Policy, Universidad de California-Berkeley, Profesor de Derecho, Universidad Diego Portales.

2 Matías Guiloff, Magíster en Derecho Universidad de Columbia, U.S.A., Profesor de Derecho, Universidad Diego Portales.

${ }^{3}$ Rodrigo Delaveau "Profesor Auxiliar Asociado de Derecho Constitucional, Facultad de Derecho Pontificia Universidad Católica de Chile. preguntas planteadas por los editores de la $R e$ vista Chilena de Derecho y en el espacio de la sección de la Revista destinada a ello.

"Hemos comenzado analizando el contexto regulatorio de la actividad farmacéutica en Chile, en particular, si el Estado tiene facultades legales y reglamentarias para obligar a quienes deseen incorporarse a dicha actividad económica a tener a disposición del público la mencionada píldora. Esto es importante para el desarrollo del argumento central, que defiende la idea que siendo la actividad farmacéutica una que provee bienes públicos básicos, y no estando nadie obligado a participar en ella, el gobierno puede imponer a las farmacias la obligación de poner a disposición del público determinados medicamentos, incluida la píldora del día después. Por lo dicho, si alguna persona siente que esta carga la obliga a violar sus principios o sus creencias debiera abstenerse de entrar o de seguir en esta actividad. De otra manera, un aspecto tan fundamental para las políticas públicas de salud, como lo es el asegurar a la población la provisión de medicamentos, quedaría entregado a la voluntad de cada individuo".

R. D: "En primer lugar, la 'objeción de conciencia' y la 'libertad de conciencia', consagrada esta última en el Art. 19 No 6 de la Constitución Política, no son conceptos idénticos. La primera se considera como un rechazo al cumplimiento de determinadas normas jurídicas por ser estas contrarias a las creencias éticas o religiosas de una persona. Su expresión más común suele ser frente al servicio militar, no obstante poder plantearse hipotéticamente ante cualquier tipo de norma positiva. La segunda, en cambio, está configurada como una libertad o una garantía en el sentido liberal, como una libertad negativa, en virtud de la cual el Estado y terceros deben refrenarse de ejercer actos u omisiones que perturben el pleno ejercicio de este derecho, relacionado preferentemente con el ejercicio del culto y la religión.

"Si bien el iusnaturalismo considera que existe un orden normativo superior al Derecho 
positivo, la objeción de conciencia se encapsula como una facultad de resistir los mandatos de la autoridad cuando contradicen los principios emanados del Derecho natural. También la Declaración Universal de los Derecho del Hombre, que la define como resistencia a la opresión, reconoce ciertos límites. Luego, si el ordenamiento jurídico no contempla mecanismo para hacer valer este derecho, si no se dispone de un sistema normativo de protección de derechos esenciales, si no existe una judicatura, un debido proceso, e instrumentos formales para ejercer estas garantías, ni límite al gobernante, solo ahí estaremos en un escenario probable en que eventualmente pueda ejercerse este derecho. Pero definitivamente, este no es el caso chileno. Por el contrario, ha sido la propia Constitución la que ha trazado un orden institucional, un sistema de protección de derechos, un juego de pesos, contrapesos y límites al poder estatal, mecanismos formales y transparentes de formación de la ley y de judicatura independiente, donde todos quedan sometidos a su imperio. Es en definitiva, un Estado de Derecho.

"Aún así cabe preguntarse si ante la situación de que tres importantes cadenas de farmacias han sido sancionadas por la autoridad de salud por no contar en su stock con unidades de la 'píldora del día después', pueden invocar la denominada objeción de conciencia o la libertad de conciencia. La verdad es que ni la una ni la otra parecen salidas efectivas a este dilema, y están lejos de aportar mucho al debate, toda vez que se ha tornado una discusión 'moralista' a veces llamada 'valórica'. Y es que el ordenamiento institucional chileno entrega -afortunadamente- suficientes herramientas de solución. De ahí que el conflicto esté resuelto mucho antes a nivel legal y constitucional que, precisamente, nos alejan de un conflicto estéril”.

2. Estima usted que los propietarios y/o los farmacéuticos pueden hacer objeción de conciencia respecto de la venta de ciertos fármacos, incluidos los del Formulario Nacional?

J. C. y M. G: "Como se señaló en la sección anterior, el mercado farmacéutico se encuentra altamente regulado. En consecuen- cia, es uno en que los agentes económicos no gozan de libertad absoluta. La justificación para tan elevados niveles de regulación es el rol que juegan las farmacias en las políticas de salud que debe implementar el gobierno para cumplir con su deber de velar por la salubridad pública, así como el riesgo involucrado en la venta de medicamentos.

"Entre las numerosas disposiciones legales y reglamentarias que regulan la actividad de las farmacias se encuentran aquellas que prescriben el deber de las mismas de poner a disposición del público todos los medicamentos que se encuentren incluidos en el Formulario Nacional, como la píldora del día después. En primer término, cabe tener presente el artículo $100 \mathrm{del}$ Código Sanitario, que establece los deberes del Ministerio de Salud, entre los cuales se encuentra el aprobar un Formulario Nacional de medicamentos, para lo cual puede tomar las medidas necesarias para que la población se encuentre permanentemente abastecida de los productos farmacéuticos que lo componen.

"Esta disposición está complementada por los artículos 15, 92 y 93 del 'Reglamento de Farmacias, Droguerías, Almacenes Farmacéuticos, Botiquines y Depósitos', contenidos en el Decreto Supremo 466 del Ministerio de Salud. El primero de los artículos mencionados establece la obligación de las farmacias de contar de manera permanente con aquellos productos establecidos en el título IX de la misma regulación. El artículo 92 -que concretiza la obligación que el artículo 15 enuncia-, por su parte, dispone que las farmacias deberán contar permanentemente con aquellos productos que se encuentren contenidos dentro del Formulario Nacional, salvo las excepciones que se contemplan en el artículo 93, ninguna de las cuales dice relación con los productos que para efectos de este comentario interesan.

"En el mismo sentido, debe hacerse referencia a la disposición contenida en el artículo 4 del Decreto Supremo 264 del Ministerio de Salud, que reitera el deber de tener a disposición del público aquellos medicamentos que se encuentren contenidos en el Formulario Nacional, deber que se mantiene incluso cuando los medicamentos no se encuentren comercializados en el país, tratándose de situaciones excep- 
cionales y para los propósitos de usos medicinales urgentes. Así las cosas, debe concluirse que, estando un medicamento contenido en el Formulario Nacional, las farmacias no tienen otra opción que tenerlo a disposición del público. Tal es justamente la situación de la píldora del día después. Esta fue incluida en el Formulario Nacional en marzo de 2006 por medio del Decreto Supremo 194 del Ministerio de Salud. En concreto el DS 194 incluyó el levonorgestrel, principio activo de la píldora del día después, pasando esta a constituir uno de aquellos medicamentos que permanentemente las farmacias deben poner a disposición del público.

"Con todo, frente a las disposiciones citadas más arriba se ha esgrimido por parte de quienes niegan la existencia de una obligación de las farmacias de vender la píldora del día después una contenida en el artículo 102 del Código Sanitario, que establece que ningún producto farmacéutico puede ser comercializado en el país sin estar previamente registrado en el Instituto de Salud Pública. En este sentido, los grupos mencionados han señalado que la distribución de la píldora (particularmente a través del producto Optinor) por parte de la Central Nacional de Abastecimiento y la ONG Aprofa no cumpliría con todos los requisitos legales, por cuanto Optinor hasta el día de hoy no cuenta con registro sanitario.

"El problema con esta argumentación es que no considera que el inciso segundo de la normativa citada contempla la posibilidad que la autoridad sanitaria establezca autorizaciones provisorias para poder vender o usar productos farmacéuticos, sin necesidad de previo registro, para usos medicinales urgentes, de investigación científica o de ensayos clínicos. Cabe señalar adicionalmente que a la fecha el producto Pregnon del Laboratorio Family Care cuenta con registro sanitario, por lo que la distribución de la píldora del día después se encuentra en la situación normal prevista por la ley.

R. D: "Antes de invocar cualquier objeción, debemos preguntarnos si el Estado tiene o no derecho para imponer esa medida. En una sociedad de libertades, el Estado tiene límites. El surgimiento del Estado de Derecho moderno (y del Constitucionalismo) tiene, entre sus ra- zones principales, la protección del individuo frente al poder ilimitado que solía ejercer el rey o el Estado. En este contexto, el Derecho se levanta como la principal garantía que obliga tanto a gobernados como a las autoridades en el ejercicio de sus poderes. El Estado solo podría obligar a una persona a hacer aquello que esta no desea si una ley lo establece. Así ocurre a diario en nuestras vidas -quizás más de la cuenta- cuando el Estado nos obliga a pagar impuestos, realizar trámites, celebrar cierto tipo de contratos con cláusulas a las que no podemos renunciar, etc. De ahí que el argumento de la objeción de conciencia no sea solo equivocado e infundado, sino que sumamente peligroso, ya que podría 'autorizar' a cualquier grupo o persona a desobedecer una ley legítima. Más aún ¿qué sucedería si el gobernante invocara 'una objeción de conciencia' frente a una norma constitucional y decidiera ejercer el poder a su arbitrio? Así las cosas, no pareciera ser que la denominada objeción de conciencia sea el eje de la discusión en este caso. No obstante, son otras las disposiciones constitucionales las que están en juego y que aportan un principio de solución a este debate.

"La pregunta siguiente es entonces si la ley permite en este caso concreto que el Estado exija la venta de ciertos medicamentos. El artículo 100 del Código Sanitario dispone que 'El Ministerio de Salud Pública aprobará (...) un Formulario Nacional de Medicamentos que contendrá la nómina de los productos farmacéuticos indispensables en el pais para una eficiencia terapéutica'. Luego agrega que el 'Director General de Salud dispondrá las medidas necesarias para que la población y los servicios que presten atención médica se encuentren permanentemente abastecidos de los productos farmacéuticos que componen el Formulario Nacional de Medicamentos'.

"Como puede apreciarse, esta norma no establece directamente la obligación de que sean las farmacias las que cuenten con esos fármacos, sino que obliga al Director General de Salud a procurar la disponibilidad de tales insumos, cuestión que naturalmente debe hacer en el marco de sus facultades legales. En este sentido la norma parece perfectamente enmarcada en un sistema donde el Estado cumple un rol subsidiario, donde prima la persona. Con todo, 
las normas que efectivamente establecen la obligación a las farmacias de contar con los productos incluidos en el Formulario Nacional son el artículo 92 del 'Reglamento del Farmacias, Droguerías, Almacenes Farmacéuticos, Botiquines y Depósitos Autorizados', y el artículo $4^{\circ}$ del 'Reglamento del Formulario Nacional de Medicamentos'. Ambas normas no tienen rango de ley, sino que emanan de la potestad reglamentaria de la autoridad.

"Acá radica el corazón de la protección a los individuos: la formación de la ley, a través de un proceso público donde están los representantes del pueblo (lo que desligitima -en parte- el argumento de la objeción de conciencia), es un proceso que, si bien no es perfecto, entrega mayores garantías a las personas en cuanto a asegurarle, al menos, un espacio para alegar la protección de sus derechos: la ley es una garantía en sí misma. En cambio, la dictación de un reglamento es tradicionalmente una cuestión sin procedimientos abiertos ni instancias de discusión que transciendan a la opinión pública. Adicionalmente, conviene considerar que siempre en los decretos hay mayor espacio a la discrecionalidad. En efecto, bastaría con un simple decreto para incluir nuevos productos farmacéuticos en el Formulario Nacional. Esto puede generar situaciones complejas como la de pretender gravar a una farmacia con la obligación de tener en existencia medicamentos de alto costo que hagan inviable la continuidad del negocio, lo cual vulneraría no solo la capacidad financiera de un particular, sino que la propia libertad de empresa y la igualdad ante las cargas públicas".

3. De acuerdo a su pensamiento, jexiste en este caso un conflicto entre libre empresa y concepto de servicio público?

J. C. y M. G: "El Ministerio de Salud tiene facultades legales y reglamentarias para obligar a quienes deseen operar en el negocio farmacéutico a poner a disposición del público la píldora del día después. En lo que sigue, revisaremos si los propietarios y/o los farmacéuticos pueden hacer objeción de conciencia respecto de la obligación legal de vender dicho medicamento.
"En primer término, es importante precisar que más que un caso de objeción de conciencia, la coordinación de algunos sectores para intentar que las farmacias no vendan la píldora del día después representa una instancia de 'desobediencia civil' y no de 'objeción de conciencia'. En efecto, y como lo señala Ernesto Garzón Valdés ('Acerca de la desobediencia civil', Sistema, $\mathrm{N}^{\circ} 42$, mayo, pp. 80 y ss.,), la objeción de conciencia es un acto personal, que por lo general no busca modificar las leyes, sino circunscribir la desobediencia al caso particular. El ejemplo paradigmático de este tipo de conductas es el del pacifista o miembro de credos religiosos opuestos a la guerra que es obligado a servir en el servicio militar, y que prefiere soportar el castigo por incumplir con su obligación legal a violar su conciencia. Este caso es en efecto muy distinto a la acción concertada de sectores del país que, habiendo fracasado en su intento de prevalecer legislativamente, buscan ahora que sus opciones de política pública prevalezcan por otras vías.

"En todo caso, aun si se considerara que lo que ocurre en Chile en relación a la píldora del día después representa un caso genuino de objeción de conciencia (y no de desobediencia civil), el hecho que a diferencia del servicio militar obligatorio la ley en el caso de la píldora no imponga a nadie la obligación de operar establecimientos farmacéuticos hace improcedente alegar la objeción de conciencia.

"Finalmente, y en relación al potencial conflicto entre libre empresa y el concepto de servicio público que algunos advierten en relación con la obligación impuesta por el Ministerio de Salud a las farmacias de poner a disposición del público la píldora del día después, nos parece que este no existe, dado que el concepto de libre empresa no puede extenderse al punto de hacer inoperantes regulaciones plenamente justificadas desde el punto de las políticas de salud pública, atendido el crucial rol que juegan las farmacias en la consecución de las mismas. Por otra parte, si se aceptara la tesis de la primacía de la libre empresa por sobre la función pública, el gobierno estaría plenamente justificado en establecer farmacias estatales en cada uno de los municipios del país. 
R. D: "La Constitución ha entendido que para regular una actividad económica deber ser la ley el instrumento elegido por la autoridad y no decisiones reglamentarias que no entregan garantías suficientes del respeto a los derechos fundamentales. No debe olvidarse que la imposición de la autoridad puede generar responsabilidades legales para las farmacias. En efecto, la ley de Protección al Consumidor dispone que son responsables por los perjuicios ocasionados al consumidor, el proveedor que haya comercializado el producto y el importador que lo haya vendido. Difícil resulta aseverar que si se exige a las farmacias indemnizar los daños causados por un aborto producido por la píldora, vendrá el Estado en defensa de las farmacias argumentando que fueron obligadas a distribuirla. Así, la obligación que quiere imponer el Gobierno se sostiene sobre cuestionables bases jurídicas pues no solo carece de ley que lo autorice a hacerlo, sino que además atenta contra el derecho que tienen los gobernados a ejercer una actividad económica.

"¿Es entonces un conflicto entre libre empresa y concepto de 'servicio público'? Aun en el caso hipotético que fuera la ley la que obliga a las farmacias a vender los medicamentos que la autoridad determina, hay límites que deben respetarse. Y es aquí donde debiera centrarse lo relevante de la discusión: la libertad de empresa y el derecho a ganarse la vida honradamente, solo pueden limitarse por la Constitución o una ley, no por decreto. Los derechos a emprender y el de propiedad, no pueden ser limitados al punto de despojar al propietario o al emprendedor del núcleo esencial de esos derechos.

"Desde el punto de vista de las políticas públicas, debe también considerarse la conveniencia de una decisión que quiere transformar a privados -que son parte de un mercado- en simples mandatarios del gobernante de turno. Esta lógica, típica de gobiernos paternalistas, no se condice con una sociedad libre, donde si la población demanda el medicamento, naturalmente surgirá la oferta. No basta con argumentar, como se ha dicho, que los privados están ejerciendo una función pública. Si el Gobierno considera de suma importancia la repartición de un medicamento, debe tomar las medidas para que ello ocurra (distribuyéndolo él mismo, si lo estima necesario) pero sin dañar los derechos de las demás personas, ni desdibujar su rol subsidiario y respetuoso de la iniciativa y responsabilidad individual. En cualquier democracia moderna en que exista un aparente conflicto de derecho, existen los mecanismos jurídicos y judiciales para resolver dicha contienda.

"Lo que no resulta admisible en un Estado de Derecho es que el gobernante de turno utilice un subterfugio legal, al calificar a la 'píldora' como un medicamento, cuando es claro que el embarazo no constituye ninguna enfermedad. La autoridad ha intentado llevar la discusión a hacia un terreno pantanoso, que siempre genera polémica y tributa objetivos políticos como la denominada 'objeción de conciencia', señalando que lo que 'importa es la libertad de conciencia de las personas para tomar sus propias decisiones y no la de los dueños de las farmacias' (El Mercurio, 30 de octubre de 2007). Sin perjuicio que pareciera decir la autoridad que los propietarios de las farmacias no pueden ejercer entonces su libertad de conciencia, lo cierto es que la discusión pasa por saber si la autoridad actuó respetando la ley (primera garantía para las personas) y de si existe el derecho de las personas a ejercer un actividad comercial de la manera que lo estimen conveniente, sin restricciones discrecionales por parte del gobernante.

"El modus operandi de la autoridad no deja de ser preocupante: sin ley alguna se quiere obligar a algunos a actuar según lo determine el gobierno de turno, sin respeto a los derechos individuales. Más allá -o más acá- que un debate sobre objeción de conciencia, deberíamos ser capaces de encontrar mecanismos formales para ejercer uno de los más fundamentales derechos de toda democracia moderna: la facultad de defendernos de gobernantes que asuman poderes no asignados por los gobernados". 